\title{
Time-dependent potentiation of insulin release induced by alpha-ketoisocaproate and leucine in rats: possible involvement of phosphoinositide hydrolysis
}

\author{
W.S.Zawalich \\ Yale University School of Nursing, New Haven, Connecticut, USA
}

Summary. The ability of the amino acid leucine and its keto acid, alpha-ketoisocaproate, to induce insulin release, to initiate phosphoinositide hydrolysis, and to amplify the subsequent insulin secretory response to glucose was assessed. In islets whose inositol-containing lipids were prelabelled with myo[ $\left[2-{ }^{3} \mathrm{H}\right]$ inositol, the addition of either compound resulted in an increase in insulin output, an increase in ${ }^{3} \mathrm{H}$ efflux, rapid and significant increases in labelled inositol phosphate accumulation and a sustained increase in ${ }^{3} \mathrm{H}$ efflux after removal of the stimulant. Direct measurements of labelled inositol phosphate accumulation in islets previously stimulated with alpha-ketoisocaproate demonstrate that this sustained increase in ${ }^{3} \mathrm{H}$ efflux was the result of a persistent increase in phosphoinositide hydrolysis and was not simply a consequence of the hydrolysis of preformed inositol phosphates into more membrane permeable species. Prior exposure of islets to alpha-ketoisocaproate or leucine also resulted in an amplified secretory response to a subsequent glucose $(10 \mathrm{mmol} / \mathrm{l})$ stimulus. While peak first phase insulin release averaged $66 \pm 4$ (mean $\pm \mathrm{SEM}, n=18$ ) $\mathrm{pg} \cdot$ islet $^{-1}$. $\min ^{-1}$ from control islets, this value increased to $204 \pm 14$ and $246 \pm 11 \mathrm{pg} \cdot$ islet $^{-1} \cdot \mathrm{min}^{-1}$ in the leucine or alpha-ketoisocaproate pretreated islets respectively. The duration of this amplified response paralleled the duration of the persistent increase in ${ }^{3} \mathrm{H}$ efflux. Prior alpha-ketoisocaproate exposure also amplified the subsequent insulin secretory response to tolbutamide and glyceraldehyde. While control (non-pretreated) islets in response to tolbutamide $(200 \mu \mathrm{mol} / \mathrm{l})$ released insulin at a rate of $50 \pm 6 \mathrm{pg} \cdot$ islet $^{-1} \cdot \min ^{-1}(n=3)$, this first phase response increased to $506 \pm 38 \mathrm{pg} \cdot$ islet $^{-1}$. $\min ^{-1}$ in prior alpha-ketoisocaproate treated islets. Peak first and second phase insulin responses to glyceraldehyde were increased 5-fold and 2-fold, respectively, by prior alpha-ketoisocaproate. These results suggest that events coupled to the hydrolysis of membrane inositol-containing phospholipids induced by leucine and alpha-ketoisocaproate participate not only in their acute insulin stimulatory action, but also in their ability to induce time-dependent potentiation (memory) in isolated islets.

Key words: Islets, phosphoinositides, memory, insulin secretion, leucine, alpha-ketoisocaproate, ${ }^{3} \mathrm{H}$ efflux.
It is well established that prior glucose stimulation of pancreatic $B$ cells results in an amplified insulin secretory response to a second glucose challenge [1-4]. Some characteristics of this phenomenon, termed timedependent potentiation (TDP) by Grill and associates $[2,3]$ have been established: (a) glucose must be metabolised to induce TDP; (b) TDP develops within minutes and persists long after removal of the initial stimulant; (c) intracellular accumulation of cAMP does not seem to play a major role in the process; and (d) glyceraldehyde and the gut hormone cholecystokinin [5] mimic to a large extent this sensitising effect of glucose. We recently reported that TDP noted with glucose [6], glyceraldehyde [6], or cholecystokinin [7], appeared to depend on agonist-induced increases in phosphoinositide (PI) hydrolysis, a response that persists despite stimulant removal. The duration of TDP parallels to a remarkable extent the duration of the sustained increase in PI hydrolysis and, moreover, conditions which abolish PI hydrolysis abolish TDP. In the present report, the capacity of leucine and alphaketoisocaproate (KIC) to promote PI hydrolysis and to induce TDP was assessed. These particular stimulants were chosen because they both augment insulin output from the B cell, an effect that seems to be related, at least in part, to their ability to increase PI metabolism [8-10]. The present results further emphasize the involvement of biochemical events in the inositol cycle in the induction of TDP by various stimulants.

\section{Material and methods}

Male Sprague-Dawley rats purchased from Charles River were used in all studies. The animals were fed ad libitum and weighed between 

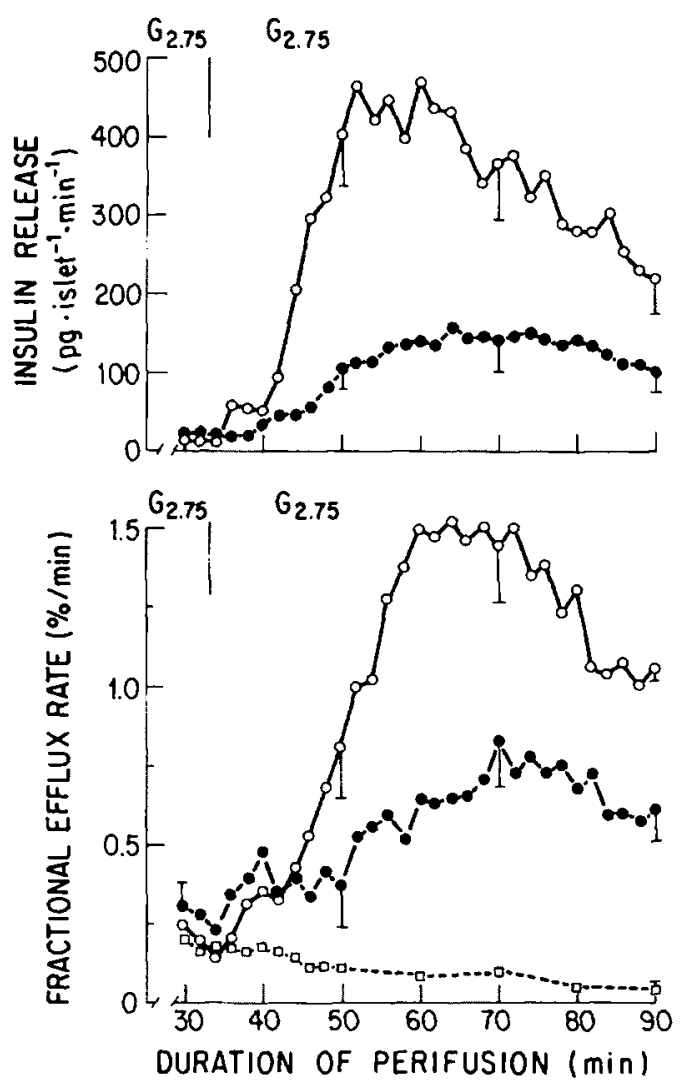

Fig. $1 \mathrm{a}$ and b. Insulin release and phosphoinositide hydrolysis in response to alpha-ketoisocaproate (KIC) and leucine. a After a $2 \mathrm{~h}$ labelling period with myo $\left[2-{ }^{3} \mathrm{H}\right]$ inositol, batches of islets were perifused with $2.75 \mathrm{mmol} / 1$ glucose for $30 \mathrm{~min}$ to establish stable basal rates of insulin secretion. They were then stimulated for $60 \mathrm{~min}$ with $\mathrm{KIC}, 15 \mathrm{mmol} / \mathrm{l},(\mathrm{O})$ or leucine, $20 \mathrm{mmol} / \mathrm{l},(-)$ with glucose still present. This and all subsequent figures have been corrected for the dead space ( $3 \mathrm{ml}$, equivalent to $3 \mathrm{~min}$ with a flow rate of $1 \mathrm{ml} / \mathrm{min}$ ) in the perifusion system. Mean values are given \pm selected SEM's of at least 4 experiments. b Fractional efflux rates of ${ }^{3} \mathrm{H}$, used to monitor PI hydrolysis are depicted here in response to $\mathrm{KIC}(\mathrm{O})$ and leucine (@). Efflux rates in response to $2.75 \mathrm{mmol} / 1$ glucose alone ( $\square$ ) are also shown. These values were calculated according to the procedure of Borle et al. [25] and were obtained from the same islets whose insulin release profiles are given above

$300-400 \mathrm{~g}$. After nembutal-induced $(50 \mathrm{mg} / \mathrm{kg})$ anaesthesia, islets were isolated by collagenase digestion [11]. In some experiments, islets were directly perifused to assess secretory responsiveness. In other experiments batches of 40-80 islets were loaded onto nylon filters and placed in small glass vials. They were incubated for $2 \mathrm{~h}$ in $200 \mu \mathrm{l}$ of a myo $\left[2{ }^{3} \mathrm{H}\right]$ inositol containing solution prepared by adding $10 \mu \mathrm{Ci}$ myo[2- $\left.{ }^{3} \mathrm{H}\right]$ inositol (initial specific activity $16.6 \mathrm{Ci} /$ mmol) to $250 \mu$ of incubation medium. The medium used for this incubation procedure was similar to that employed during the islet perifusion and consisted of $115 \mathrm{mmol} / \mathrm{l} \mathrm{NaCl}, 5 \mathrm{mmol} / 1 \mathrm{KCl}$, $2.2 \mathrm{mmol} / 1 \mathrm{CaCl}_{2}, 1 \mathrm{mmol} / \mathrm{l} \mathrm{MgCl}_{2}, 24 \mathrm{mmol} / 1 \mathrm{NaHCO}_{3}$, and $0.17 \mathrm{~g}$ $\%$ bovine serum albumin. The solution was gassed with $95 \% \mathrm{O}_{2} / 5 \%$ $\mathrm{CO}_{2}$. Glucose $(2.75 \mathrm{mmol} / \mathrm{l})$ was also present during the incubation. After termination of the incubation the islets, still attached to the nylon filters, were washed with $5 \mathrm{ml}$ nonradioactive medium and perifused. The $\mathrm{pH}$ of the perifusion medium was maintained at 7.4, the temperature at $37^{\circ} \mathrm{C}$, and the flow rate at $1 \mathrm{ml} / \mathrm{min}$. Islets were usually perifused for $30 \mathrm{~min}$ to establish stable insulin secretory rates and then exposed to various agonists indicated in the figure legends. Perifusate samples were collected at time intervals indicated in the figures and $200 \mu \mathrm{l}$ aliquots analysed for ${ }^{3} \mathrm{H}$ content when appropri-
Table 1. Influence of leucine $(20 \mathrm{mmol} / 1)$ and alpha-ketoisocaproate $(15 \mathrm{mmol} / \mathrm{l})$ on inositol phosphate accumulation in isolated perifused rat islets

\begin{tabular}{|c|c|c|c|}
\hline \multirow{2}{*}{$\frac{\text { Protocol }}{(\min )}$} & $\mathbf{I P}_{1}$ & $\mathrm{IP}_{2}$ & $\mathrm{IP}_{3}$ \\
\hline & \multicolumn{3}{|c|}{$(\mathrm{cpm} / 40$ islets, mean $\pm \mathrm{SE})$} \\
\hline $\begin{array}{l}\text { 1. } \mathrm{G}_{275} \\
(50 \text { or } 60 \mathrm{~min})\end{array}$ & $413 \pm 30$ & $111 \pm 12$ & $98 \pm 9$ \\
\hline $\begin{array}{l}\text { 2. } \mathrm{G}_{2,75} \rightarrow \mathrm{G}_{2,75}+\text { Leucine } \\
\begin{array}{l}(30) \quad(20)\end{array}\end{array}$ & $621 \pm 62$ & $168 \pm 13$ & $129 \pm 7$ \\
\hline $\begin{array}{l}\text { 3. } G_{2.75} \\
\text { (32) }\end{array}$ & $406 \pm 23$ & $103 \pm 13$ & $88 \pm 7$ \\
\hline $\begin{array}{l}\text { 4. } \mathrm{G}_{275} \rightarrow \mathrm{G}_{275}+\mathrm{KIC} \\
\begin{array}{l}(30) \\
\text { (2) }\end{array}\end{array}$ & $660 \pm 38$ & $179 \pm 11$ & $167 \pm 12$ \\
\hline $\begin{array}{l}\text { 5. } \mathrm{G}_{275} \rightarrow \mathrm{G}_{2.75}+\mathrm{KIC} \\
(30)(20)\end{array}$ & $1082 \pm 139$ & $527 \pm 116$ & $283 \pm 61$ \\
\hline $\begin{array}{l}\text { 6. } \mathrm{G}_{275} \rightarrow \mathrm{G}_{275}+\mathrm{LiCl} \\
(60) \quad(20)\end{array}$ & $504 \pm 41$ & $95 \pm 14$ & $98 \pm 18$ \\
\hline $\begin{array}{l}\text { 7. } \mathrm{G}_{275} \rightarrow \mathrm{G}_{2,75}+\mathrm{KIC} \rightarrow \mathrm{G}_{275} \\
(30)(20)\end{array}$ & $637 \pm 29$ & $182 \pm 21$ & $108 \pm 17$ \\
\hline $\begin{array}{l}\text { 8. } \mathrm{G}_{2,75} \rightarrow \mathrm{G}_{2,75}+\mathrm{KIC} \rightarrow \\
(30)(20) \\
\mathrm{G}_{2,75} \rightarrow \mathrm{G}_{2,75}+\mathrm{LiCl} \\
(10)(20)\end{array}$ & $1540 \pm 181$ & $280 \pm 28$ & $197 \pm 18$ \\
\hline
\end{tabular}

After labelling for $2 \mathrm{~h}$ with myo[2-3 H]inositol, groups of islets $(n=\mathrm{at}$ least 4 for each condition) were perifused as indicated. After the perifusion, inositol phosphates were extracted with $10 \%$ perchloric acid and separated as described [13,14]. Statistical analysis is as follows: Protocol 1 vs Protocol $2-\mathrm{p}<0.05$ for all inositol phosphates, Protocol 1 vs Protocol 5 - p $<0.05$ for all inositol phosphates, Protocol 1 vs Protocol 6 - no significant differences, Protocol 3 vs Protocol $4-p<0.05$ for all inositol phosphates, Protocol 5 vs Protocol 7 $\mathrm{p}<0.05$ for $\mathrm{IP}_{1} ; \mathrm{IP}_{2}$, and $\mathrm{IP}_{3}$, Protocol 6 vs Protocol $8-\mathrm{p}<0.05$ for all inositol phosphates

Abbreviations: $I P_{1}$ - inositol 1-phosphate; $I P_{2}$ - inositol 1,4-bisphosphate; $\mathrm{IP}_{3}$ - inositol 1,4,5-trisphosphate; +1,3,4-trisphosphate; LiCl-lithium chloride, $10 \mathrm{mmol} / 1$

ate as well as insulin [12] using rat insulin (Lilly and Co., Indianapolis, Indiana, USA \#615-D63-12-3) as standard. In some experiments the nature of the ${ }^{3} \mathrm{H}$-containing molecules was assessed in pooled perifusate samples collected during the final $10 \mathrm{~min}$ of the perifusion. In other experiments, the levels of free ${ }^{3} \mathrm{H}$-inositol, glycerophosphoinositol (GPI) and labelled inositol phosphates were determined after extraction with $10 \%$ perchloric acid by methods previously detailed [13, 14]. Briefly, after neutralisation with $0.25-0.28 \mathrm{ml} 6 \mathrm{~N} \mathrm{KOH}$, the further addition of $5 \mathrm{ml}$ water, and centrifugation, the supernatant was applied to columns. These columns were prepared by adding (to achieve a length of $3 \mathrm{~cm}$ ) anion exchange resin (AG \#1-8X Bio-Rad Labs, Richmond, Calif, USA) to Pasteur pipettes. Further additions to the column included $10 \mathrm{ml}$ water (to elute free ${ }^{3} \mathrm{H}$-inositol) and $5 \mathrm{ml} 5 \mathrm{mmol} / / \mathrm{Borax} / 60 \mathrm{mmol} / \mathrm{l}$ sodium formate (to elute GPI). Elution of the inositol phosphates was accomplished by the sequential addition of $10 \mathrm{ml} 0.1 \mathrm{~mol} / 1$ formic acid $/ 0.2 \mathrm{~mol} / 1$ ammonium formate $\left(\mathrm{IP}_{1}\right), 0.1 \mathrm{~mol} / 1$ formic acid/ $0.4 \mathrm{~mol} / 1$ ammonium formate $\left(\mathrm{IP}_{2}\right)$ and $0.1 \mathrm{~mol} / 1$ formic acid/ $1 \mathrm{~mol} / 1$ ammonium formate $\left(I \mathrm{P}_{3}\right)$. This procedure does not differentiate between various inositol trisphosphate isomers. Aliquots $(0.4 \mathrm{ml})$ of the eluate were then analysed for radioactive contents. The radioisotope used to measure insulin relcase $\left({ }^{125}\right.$ l-insulin) was purchased from New England Nuclear (Boston, Mass, USA) and the myo $\left[2-{ }^{3} \mathrm{H}\right]$ inositol from Amersham (Arlington Hts., IIl, USA). Leucine and alpha-ketoisocaproate (sodium salt), borax, formic acid and D-glyceraldehyde were purchased from Sigma Chemical Co. 
(St.Louis, Mo, USA). Ammonium formate was purchased from Fisher Scientific Co. (Fair Lawn, NJ, USA). Tolbutamide (sodium salt) was the generous gift of Upjohn Co. (Kalamazoo, Mich, USA).

\section{Statistical analysis}

Where appropriate, statistical significance was determined using the Student's t-test for unpaired data and a $p$ value less than 0.05 was taken as significant. Values presented in the figures represent means $\pm S E M$ of the specified number of observations.

\section{Results}

After a $2 \mathrm{~h}$ incubation period with myo[ $\left.2-{ }^{3} \mathrm{H}\right]$ inositol to label their inositol-containing phospholipids, batches of islets were perifused with $2.75 \mathrm{mmol} / 1$ glucose for $30 \mathrm{~min}$ to establish basal insulin secretory rates. Subsequent exposure to $15 \mathrm{mmol} / 1 \mathrm{KIC}$ or $20 \mathrm{mmol} / 1$ leucine (in the continued presence of $2.75 \mathrm{mmol} / 1 \mathrm{glu}$ cose) was accompanied by an increased output of insulin (Fig. 1, top). The response to $\mathrm{KIC}(15 \mathrm{mmol} / \mathrm{l})$ was significantly $(p<0.05)$ greater at most time points than that noted to leucine $(20 \mathrm{mmol} / \mathrm{l})$. Insulin release rates in response to both agonists tended to fall somewhat during the final minutes of the $60 \mathrm{~min}$ stimulation period.

A situation similar to that noted with insulin secretion, at least in quantitative terms, was observed when ${ }^{3} \mathrm{H}$ efflux rates were monitored in these same islets (Fig. 1, bottom). While prestimulatory efflux rates were comparable in the presence of $2.75 \mathrm{mmol} / 1$ glucose

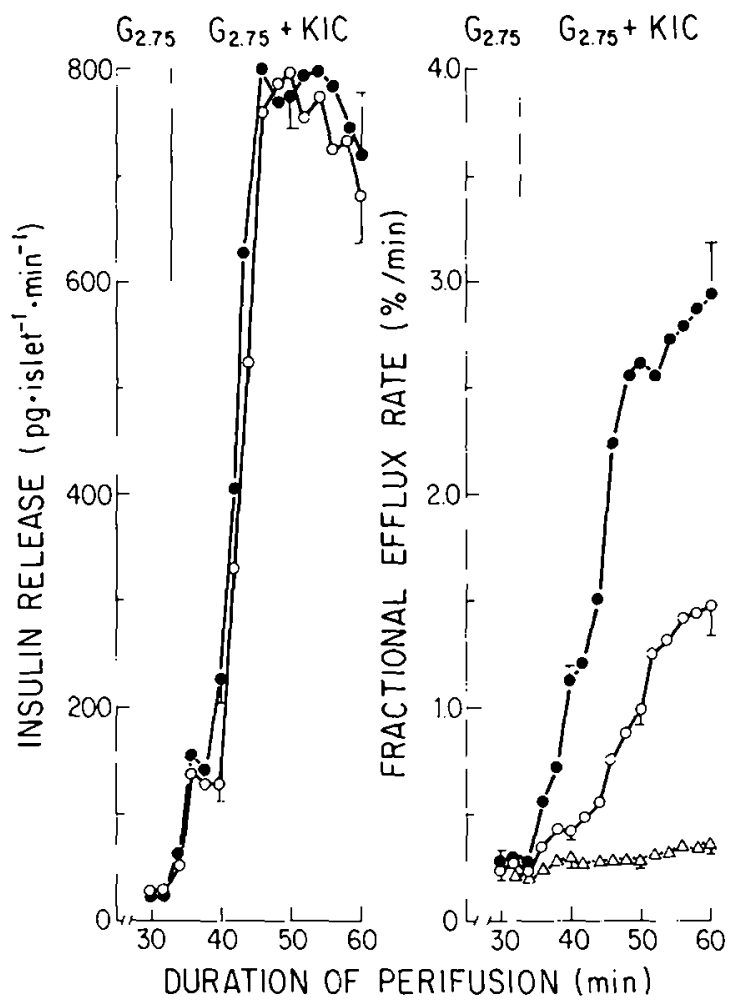

Fig. 2. Nonradioactive inositol increases ${ }^{3} \mathrm{H}$ efflux in response to KIC. Groups of $60-80$ islets were incubated for $2 \mathrm{~h}$ with myo[ $\left[-{ }^{3} \mathrm{H}\right]$ inositol, washed with fresh medium and then perifused. Insulin secretory rates (left panel) and fractional rates of ${ }^{3} \mathrm{H}$ efflux (right panel) were measured in response to $15 \mathrm{mmol} / \mathrm{I} \mathrm{KIC} \mathrm{alone} \mathrm{(O)} \mathrm{or} \mathrm{KIC}$ plus $1 \mathrm{mmol} / 1$ nonradioactive inositol $(\bigcirc)$. Fractional efflux rates of ${ }^{3} \mathrm{H}$ in response to $2.75 \mathrm{mmol} / \mathrm{l}$ glucose plus $1 \mathrm{mmol} / \mathrm{l}$ inositol are also depicted $(\Delta)$

Table 2. Effect of alpha-ketoisocaproate (KIC) stimulation on islet and effluent levels of ${ }^{3}$ H-inositol (INS), glycerophosphoinositol (GPI), inositol monophosphate $\left(\mathrm{IP}_{1}\right)$, inositol bisphosphate $\left(\mathrm{IP}_{2}\right)$ and inositol trisphosphate $\left(\mathrm{IP}_{3}\right)$

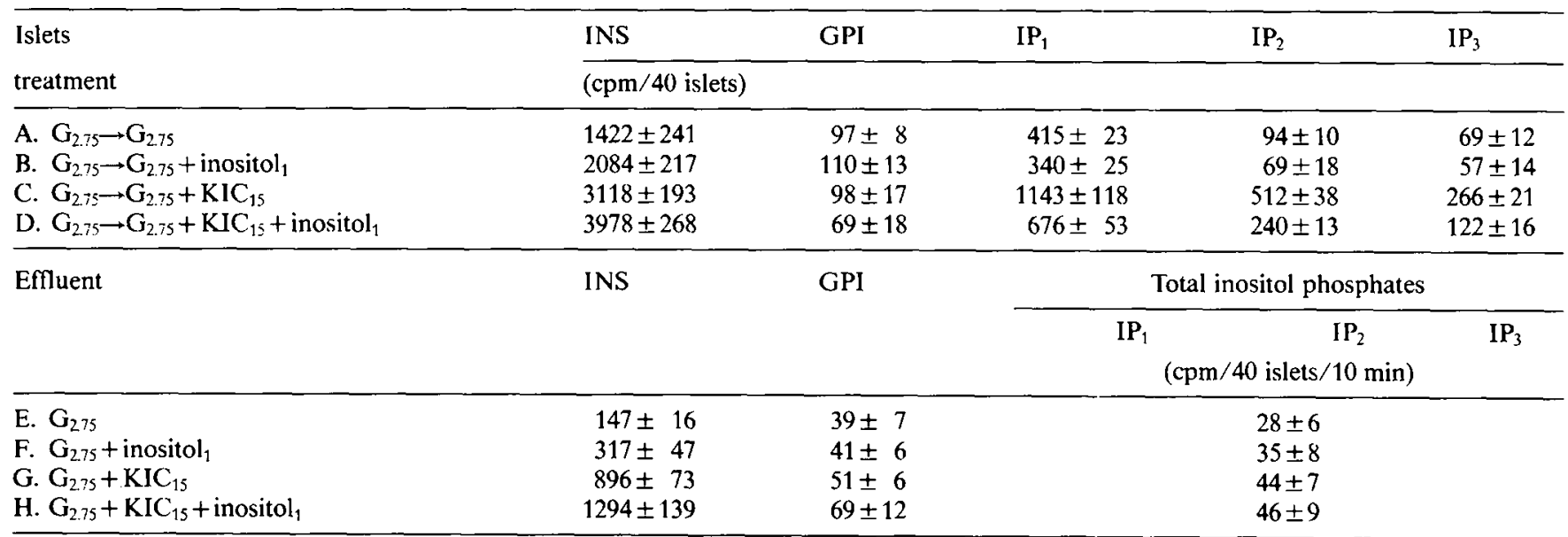

After a $2 \mathrm{~h}$ incubation with $\left(2-{ }^{3} \mathrm{H}\right)$ inositol to label the phosphoinositides, groups of $60-80$ islets were washed and then perifused for 30 min with $2.75 \mathrm{mmol} / \mathrm{l}$ glucose to establish basal stable ${ }^{3} \mathrm{H}$ efflux and insulin secretion rates. Some islets (A) were maintained with $2.75 \mathrm{mmol} / 1$ glucose for an additional $30 \mathrm{~min}$ while other groups were exposed to $2.75 \mathrm{mmol} / 1$ glucose plus $1 \mathrm{mmol} / 1$ inositol (B), $2.75 \mathrm{mmol} / 1 \mathrm{glucose}$ plus $15 \mathrm{mmol} / \mathrm{I} \mathrm{KIC} \mathrm{(C),} \mathrm{or} 2.75 \mathrm{mmol} / 1$ glucose plus $15 \mathrm{mmol} / 1 \mathrm{KIC}$ plus $1 \mathrm{mmol} / 1$ inositol (D). The numbers given in subscript indicate the millimolarity of the compound. At the termination of the perifusion, the islets were placed in $10 \%$ perchloric acid (PCA) and the various compounds measured as described in the methods section. Effluent samples were collected during the final 10 min of the perifusion with the substances indicated and pooled $5 \mathrm{ml}$ samples acidified with $500 \mu \mathrm{l} \mathrm{PCA}$. After neutralisation with $6 \mathrm{~N} \mathrm{KOH}$ and centrifugation, samples were analysed for content of the various substances. At least 4 experiments were performed under each condition. Mean values \pm SEM are given. Because the levels of the individual labelled inositol phosphates were so low in the effluent, they were extracted togehter by the addition of $10 \mathrm{ml} 0.1 \mathrm{~mol} / 1$ formic acid $+1 \mathrm{~mol} / 1$ ammonium formate. Statistical analysis: line A vs line $\mathrm{B}-p<0.05$ for inositol and $\mathrm{IP}_{1}$; line $\mathrm{C}$ vs line $\mathrm{D}$ $p<0.05$ for inositol, $\mathrm{IP}_{1}, \mathrm{IP}_{2}$ and $\mathrm{IP}_{3}$; line $\mathrm{E}$ vs line $\mathrm{F}, p<0.05$ for inositol; line $\mathrm{G}$ vs line $\mathrm{H}, p<0.05$ for inositol 


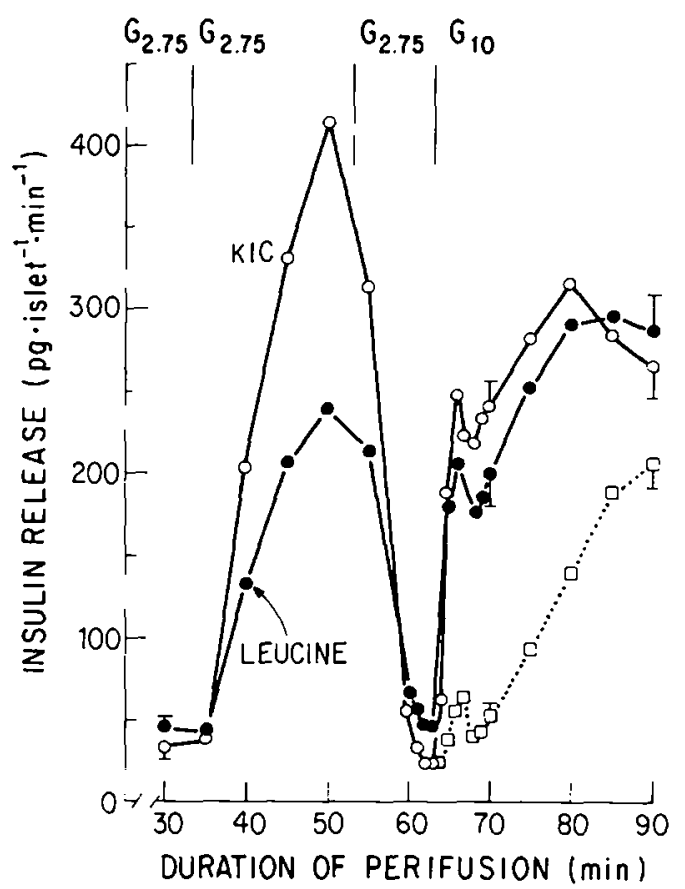

Fig. 3. Time-dependent potentiation (memory) induced by $\mathrm{KIC}$ and leucine. Freshly isolated islets were perifused for $30 \mathrm{~min}$ with $2.75 \mathrm{mmol} / 1$ glucose and for an additional $20 \mathrm{~min}$ with $\mathrm{KIC}$, $15 \mathrm{mmol} / \mathrm{l}(\mathrm{O})$ or leucine, $20 \mathrm{mmol} / \mathrm{l}(\mathrm{O})$. After a $10 \mathrm{~min}$ washout period with $2.75 \mathrm{mmol} / \mathrm{l}$ glucose alone, the islets were stimulated for $30 \mathrm{~min}$ with $10 \mathrm{mmol} / 1$ glucose ( $n=5$ for each condition). The response of islets perifused with $2.75 \mathrm{mmol} / 1$ glucose alone ( $\square$ ) prior to stimulation with $10 \mathrm{mmol} / 1$ glucose is also depicted. The responses of control islets, maintained for 60 or $70 \mathrm{~min}$ with $2.75 \mathrm{mmol} / 1$ glucose prior to stimulation with $10 \mathrm{mmol} / 1$ glucose were virtually identical and pooled values for these experiments $(n=18)$ are presented here. The control responses presented in Figure 4 (left panel) were similarly calculated

(approximately $0.25 \% / \mathrm{min}$ ), the addition of $\mathrm{KIC}$ or leucine was accompanied by quantitatively disparate increases in perifusate ${ }^{3} \mathrm{H}$. KIC $(15 \mathrm{mmol} / \mathrm{l})$ again proved to be significantly $(p<0.05)$ more effective than leucine $(20 \mathrm{mmol} / \mathrm{l})$. Also, and similar to insulin release rates, ${ }^{3} \mathrm{H}$ efflux rates fell somewhat during the final phase of stimulation with both compounds. A $20 \mathrm{~min}$ exposure to $\mathrm{KIC}$ or leucine also resulted in a significant increase $(p<0.05)$ in the levels of islet inositol phosphates (Table 1, lines 2 and 5). Consistent with the insulin release results and ${ }^{3} \mathrm{H}$ efflux data, the effect of KIC was significantly greater $(p<0.05)$ than leucine. KIC significantly $(p<0.05)$ increased islet levels of labelled inositol phosphates within $2 \mathrm{~min}$ after KIC exposure (Table 1, line 4).

In a previous report [15], we demonstrated that the inclusion of nonradioactive inositol $(1 \mathrm{mmol} / \mathrm{l})$ in the perifusion medium improved our ability to monitor glucose-induced increases in ${ }^{3} \mathrm{H}$ efflux. A similar situation occurs with KIC-stimulated islets (Fig. 2). While nonradioactive inositol had no effect on KIC-stimulated secretion (left panel), its inclusion with $15 \mathrm{mmol} / \mathrm{K} \mathrm{KIC} \mathrm{(right} \mathrm{panel)} \mathrm{resulted} \mathrm{in} \mathrm{a} \mathrm{significantly}$ greater ${ }^{3} \mathrm{H}$ efflux response $(p<0.05)$, a response that

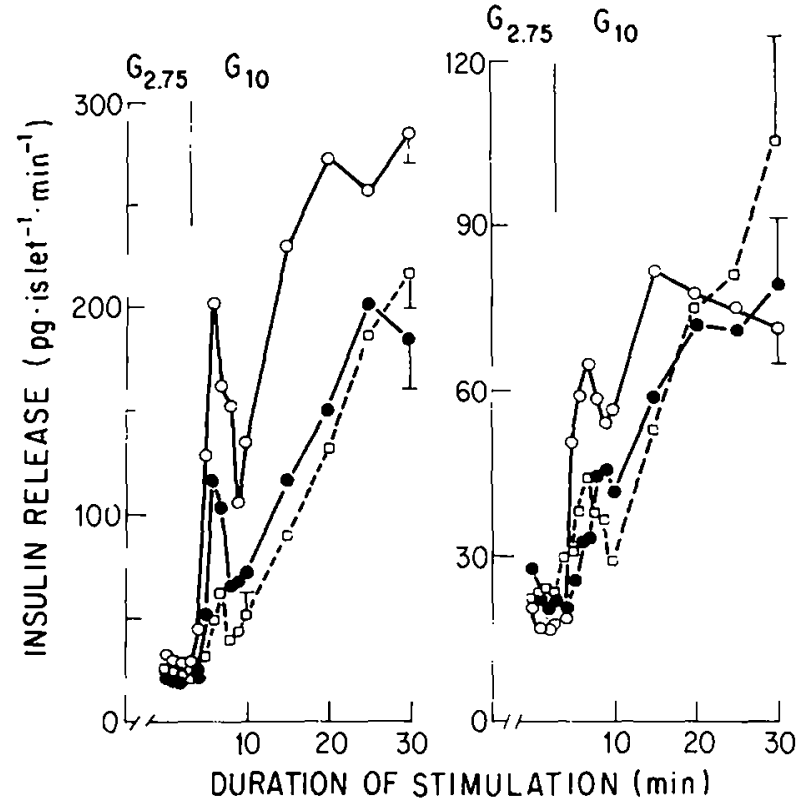

Fig.4a and b. Duration of memory induced by KIC or leucine. a Similar to the protocol outlined in Figure 3, islets were stimulated with $\mathrm{KIC}(\mathrm{O})$ or leucine $(0)$ for $20 \mathrm{~min}$. After a $20 \mathrm{~min}$ washout with $2.75 \mathrm{mmol} / 1$ glucose, the islets were stimulated with $10 \mathrm{mmol} / 1$ glucose. Only the duration of this stimulatory period is shown. The control response of islets perifused for 60 or $70 \mathrm{~min}$ with $2.75 \mathrm{mmol} / \mathrm{I}$ glucose $(\square)$ prior to stimulation with the higher hexose level is also shown. b A stimulatory protocol similar to that described previously was employed except that the interval between $\mathrm{KIC}(\mathrm{O})$ or leucine $(0)$ exposure and $10 \mathrm{mmol} / 1$ glucose stimulation was extended to $60 \mathrm{~min}$. The response of islets maintained with low glucose for $110 \mathrm{~min}$ prior to stimulation is also shown ( $\square$ )

was nearly as rapid in onset as insulin secretion. Furthermore, the inclusion of cold inositol significantly increased $(p<0.05)$ islet content of free ${ }^{3} \mathrm{H}$-inositol but significantly reduced $(p<0.05)$ the levels of labelled inositol phosphates in response to KIC stimulation (Table 2). Analysis of effluent radioactivity demonstrated that free ${ }^{3} \mathrm{H}$-inositol was the major radioactive moiety in the effluent of control and stimulated islets (Table 2). Approximately $70 \%$ of the label in the perifusate from control islets (perifused with $2.75 \mathrm{mmol} / 1$ glucose) was free ${ }^{3} \mathrm{H}$-inositol, a value that increased to over $90 \%$ when islets were stimulated with KIC alone or in the presence of $1 \mathrm{mmol} / \mathrm{l}$ nonradioactive inositol.

Our previous results with other B-cell stimulants $[5-7,16]$ support the concept that events in the inositol cycle play a crucial role in the induction and maintenance of TDP. Since both KIC and leucine activate PI hydrolysis (Fig. 1, Table 1) [8-10], we next investigated whether both compounds heighten the secretory response to a subsequent glucose stimulus. The results are shown in Figure 3. In these experiments, freshly isolated islets were perifused for $30 \mathrm{~min}$ with $2.75 \mathrm{mmol} / 1$ glucose before being provoked for $20 \mathrm{~min}$ with $\mathrm{KIC}(15 \mathrm{mmol} / \mathrm{l})$ or leucine $(20 \mathrm{mmol} / \mathrm{l})$. In response to either compound, insulin output rose. Following a $10 \mathrm{~min}$ period with $2.75 \mathrm{mmol} / 1$ glucose 

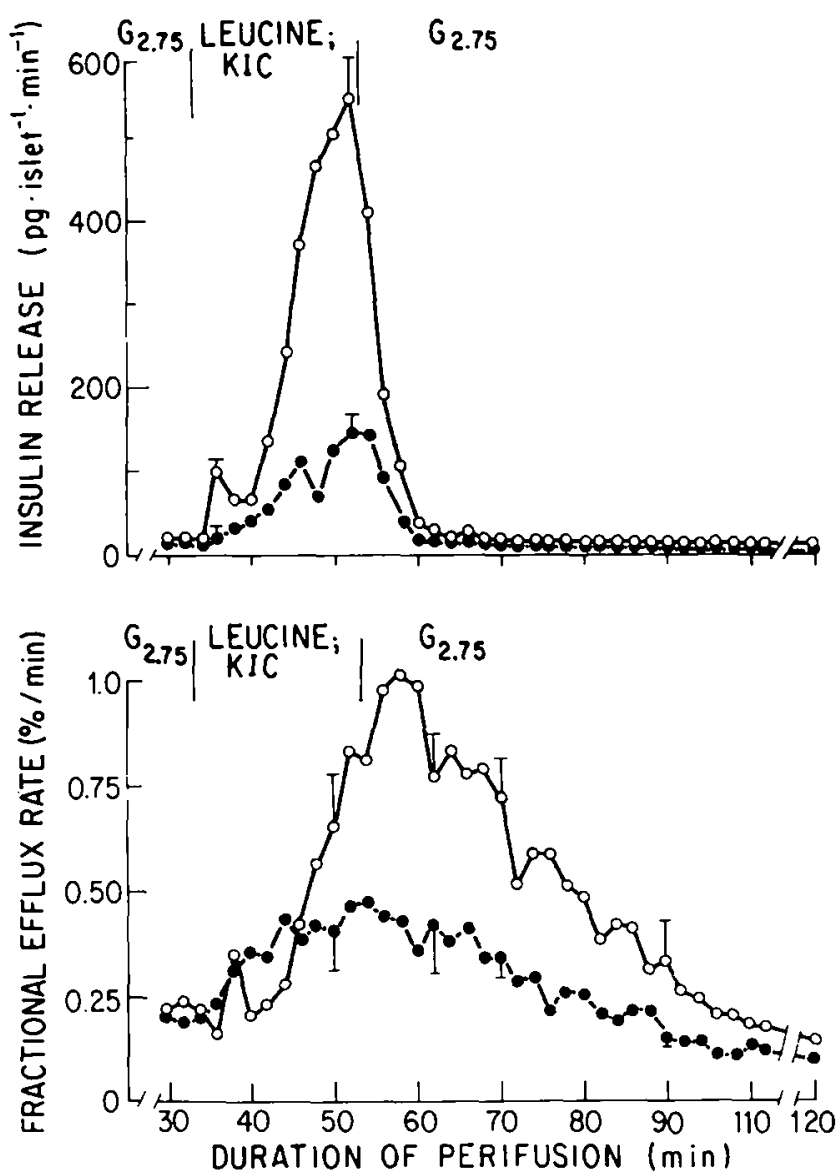

Fig.5. Sustained effect of KIC or leucine on ${ }^{3} \mathrm{H}$ efflux. After a $2 \mathrm{~h}$ prelabelling period, islets were perifused for $30 \mathrm{~min}$ with low glucose and then stimulated for $20 \mathrm{~min}$ with $\mathrm{KIC}, 15 \mathrm{mmol} / \mathrm{l}(\mathrm{O})$ or leucine, $20 \mathrm{mmol} / \mathrm{l}(\Theta)$. The perifusion was continued for an additional 50 min with $2.75 \mathrm{mmol} / 1$ glucose alone ( $n=4$ for each condition). Insulin release (top) and ${ }^{3} \mathrm{H}$ efflux rates (bottom) were measured

alone, during which time insulin release rates rapidly fell to prestimulatory values, the islets were restimulated, this time with $10 \mathrm{mmol} / 1$ glucose. The response of control islets maintained fro 60 or $70 \mathrm{~min}$ (Fig. 3 legend) with $2.75 \mathrm{mmol} / 1$ glucose alone before being provoked with $10 \mathrm{mmol} / 1$ glucose is also shown. When compared to the insulin response from these control islets, prior exposure to leucine or KIC was accompanied by a greater insulin secretory response to $10 \mathrm{mmol} / \mathrm{I}$ glucose. Particularly dramatic is the first phase response. In control islets, peak first phase release averaged $66 \pm 4(n=18) \mathrm{pg} \cdot$ islet $^{-1} \cdot \mathrm{min}^{-1}$. This value increased to $204 \pm 14$ and $246 \pm 11 \mathrm{pg}$. islet $^{-1}$. $\min ^{-1}$ in the leucine-and KIC-pretreated groups respectively. Release rates measured 25-30 min after the onset of stimulation were also significantly greater $(p<0.05)$ in the KIC-and leucine-treated islets. If the interval between the exposure to KIC or leucine and $10 \mathrm{mmol} / \mathrm{l}$ glucose was extended to 20 or $60 \mathrm{~min}$, TDP was observed only in the $20 \mathrm{~min}$ interval group (Fig. 4, left panel). In the case of KIC, both first and second phase responses were amplified. With leucine preexpo-

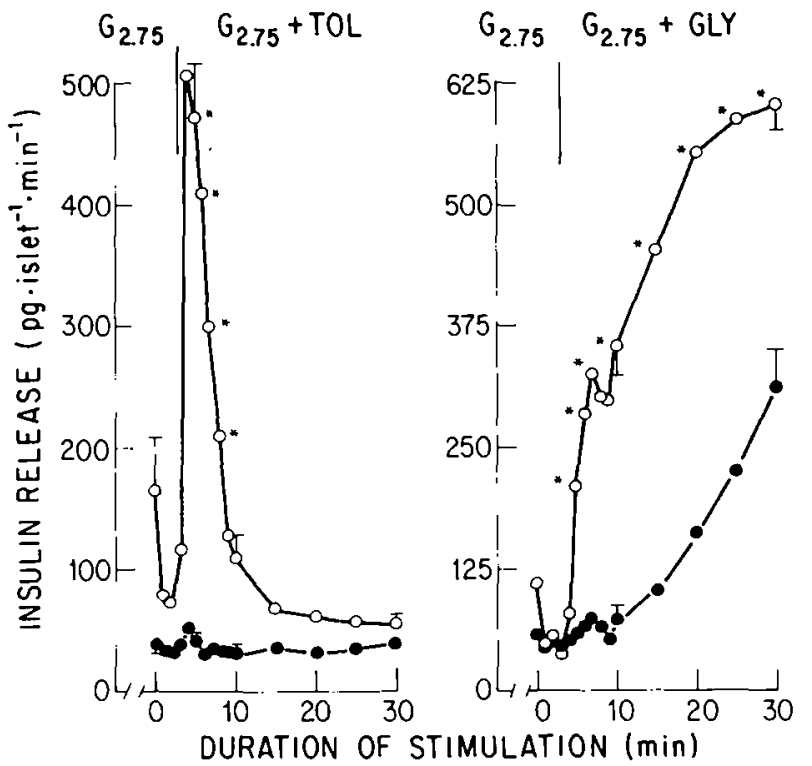

Fig. 6. Time-dependent potentiation induced by KIC to other agonists. Islets were stimulated for $20 \mathrm{~min}$ with $\mathrm{KIC}, 15 \mathrm{mmol} / \mathrm{l}(\mathrm{O})$, perifused for an additional $10 \mathrm{~min}$ with $2.75 \mathrm{mmol} / \mathrm{l}$ glucose alone, and then stimulated with $200 \mu \mathrm{mol} / 1$ tolbutamide (left panel) or $5 \mathrm{mmol} / \mathrm{l}$ glyceraldehyde (right panel). Control responses of islets not previously stimulated with KIC are also depicted (O). Only the 30 min stimulatory period with tolbutamide or glyceraldehyde is depicted here. Selected time points were analysed for statistical significance, ${ }^{*} p<0.05$. At least 3 experiments were performed under each condition

sure, only the first phase insulin secretory response was significantly increased above control release rates. Extending the interval between stimulant presentations to 60 min resulted in the abolition of TDP (Fig. 4, right panel).

We next examined the impact of a 20 min stimulatory period with either KIC or leucine on the efflux of ${ }^{3} \mathrm{H}$. The results are given in Figure 5 . While acute exposure to either compound was accompanied by insulin output (Fig. 5, top), insulin secretion rates rapidly subsided within $10 \mathrm{~min}$ after stimulant removal. In these same islets, ${ }^{3} \mathrm{H}$ efflux rates slowly increased with agonist addition (Fig. 5, bottom) but, unlike insulin secretory rates, remained elevated long after $\mathrm{KIC}$ or leucine removal from the medium. In the case of KIC, efflux rates remained significantly elevated above prestimulatory values for $40 \mathrm{~min}$. In the case of leucine, efflux rates remained elevated above prestimulatory rates for $28 \mathrm{~min}$ after stimulant removal. Of particular relevance to the notion that the persistent increase in PI hydrolysis regulates TDP, the duration of the increase in ${ }^{3} \mathrm{H}$ efflux paralleled to a large extent the duration of TDP (see Fig.4).

The concept that prior KIC exposure results in a persistent increase in PI hydrolysis was substantiated further by direct measurements of labelled inositol phosphates in prior KIC-stimulated islets (Table 1). First, KIC rapidly and significantly increased $(p<0.05)$ the levels of all inositol phosphates measured (Table 1 , 
compare lines 1 and 3 with lines 4 and 5). These levels fell after a $10 \mathrm{~min}$ perifusion with $2.75 \mathrm{mmol} / 1$ glucose alone (Table 1, line 7), but, in the case of $I P_{1}$ and $I P_{2}$, remained significantly higher than control values $(p<$ 0.05) (line 1). In other experiments control (Table 1, line 6) or prior KIC-treated islets (Table 1, line 8) were perifused for an additional $20 \mathrm{~min}$ with $2.75 \mathrm{mmol} / 1$ glucose plus $10 \mathrm{mmol} / \mathrm{l}$ lithium chloride. Lithium chloride, by blocking phosphatase action on inositol phosphates [17], allows these compounds to accumulate intracellularly. In control islets treated with $2.75 \mathrm{mmol} / 1$ glucose alone (Table 1, line 6), this manipulation has no significant effect on levels of these compounds, indicating that with low glucose PI hydrolysis is low. However, in the islets previously exposed to KIC, dramatic elevations of inositol phosphates, particularly in $\mathrm{IP}_{1}$, were noted (Table 1 , line 8 ). Since we had already established that these inositol phosphate levels decrease after removal of KIC from the perifusion medium (Table 1, line 7), a reasonable explanation for this dramatic increase in these inositol phosphates is a sustained activation of PI hydrolysis induced by prior KIC exposure. Despite these dramatic increases in islet inositol phosphate levels under this condition (prior $\mathrm{KIC}$ and subsequent exposure to $\mathrm{LiCl}$ ), there was no parallel increase in insulin output from these islets (data not shown). We attribute this observation, at least in part, to the inhibitory effect of lithium chloride on insulin output [6].

Finally, experiments were designed to test the specificity of TDP induced by KIC. The results from these studies (Fig. 6) demonstrate that a prior 20 min exposure to KIC results in an amplified secretory response to either $200 \mu \mathrm{mol} / 1$ tolbutamide (with $2.75 \mathrm{mmol} / \mathrm{l}$ glucose) or $5 \mathrm{mmol} / 1 \mathrm{D}$-glyceraldehyde.

\section{Discussion}

In a series of preceding publications $[5-7,16]$, we have explored the possible involvement of biochemical events set into motion by an increase in PI hydrolysis in the induction of B-cell memory to glucose. The phenomenon of memory has been known for some time but its biochemical basis has yet to be firmly established. Our previous results with cholecystokinin [5], glucose [6], glyceraldehyde [6], tolbutamide [16] and a report by Sorenson [18] with the phorbol ester TPA, all support the concept that events in the inositol cycle are somehow intimately involved in this process. In the present study, we have expanded the list of compounds that induce memory to glucose and, again, PI hydrolysis seems to be an integral component of this phenomenon.

In the present experiments, we employed $\mathrm{KIC}$ and leucine to activate the B cell secretory apparatus. Previous studies $[8,9]$ have established that both com- pounds increase the incorporation of ${ }^{32} \mathrm{P}$ into islet inositol containing phospholipids. KIC $(10 \mathrm{mmol} / \mathrm{l})$ has also been shown to elevate the levels of labelled inositol phosphates from islets prelabelled with $\left[2-{ }^{3} \mathrm{H}\right]$ inositol [10]. A previous report by Clements et al. [19], however, failed to document a stimulatory effect of leucine or KIC on recovery of ${ }^{3} \mathrm{H}$ inositol prelabelled PI. This observation may be attributable, at least in part, to the low rates of ${ }^{3} \mathrm{H}$ incorporated into PI and the low levels $(8-10 \mathrm{mmol} / \mathrm{l})$ of leucine or $\mathrm{KIC}$ used in these studies. Even at $20 \mathrm{mmol} / \mathrm{l}$, the impact of leucine on PI hydrolysis is modest. The present studies indicate that the quantitative impact of KIC $(15 \mathrm{mmol} / 1)$ on both insulin release and PI hydrolysis is significantly greater than leucine $(20 \mathrm{mmol} / \mathrm{l})$.

It should be emphasized that the rationale for using ${ }^{3} \mathrm{H}$ efflux rates as the index of PI hydrolysis is based on several pertinent observations previously reported. First, ${ }^{3} \mathrm{H}$-inositol is exclusively incorporated into inositol-containing phospholipids [20,21]. Second, an increase in perifusate ${ }^{3} \mathrm{H}$ is paralleled by a decrease in labelled inositol-containing phospholipids [20]. Third, it is possible to simultaneously monitor the kinetics of PI hydrolysis and insulin output in the same islets with this approach [14-16, 20]. Fourth, the functional integrity (insulin release) of the islets can be conveniently established [14-16, 20], an issue not often addressed in many previous reports on PI hydrolysis in islets. Along these lines, for example, lithium chloride is often included in the medium to facilitate the measurements of inositol phosphates generated during agonist-induced PI hydrolysis. We recently reported [6], in agreement with other studies $[22,23]$ that the level $(10 \mathrm{mmol} / \mathrm{l})$ of lithium commonly employed in many of these studies actually inhibits insulin output, thus making the extrapolation of results obtained in the presence of this cation to the dynamic insulin secretory response tenuous at best. Finally, and most importantly, the ${ }^{3} \mathrm{H}$ efflux data were substantiated, both qualitatively and quantitatively, by direct measurements of labelled inositol phosphate accumulation in perifused islets. This finding adds further credence to the concept that ${ }^{3} \mathrm{H}$ efflux from ${ }^{3} \mathrm{H}$-inositol prelabelled islets is indeed a valid index of an increase in cellular PI hydrolysis.

One possible problem with using ${ }^{3} \mathrm{H}$ efflux rates to monitor PI hydrolysis in islets is the fact that while inositol phosphates accumulate rapidly in response to KIC (Table 1, line 4), significant increases in ${ }^{3} \mathrm{H}$ efflux lag somewhat behind both this response and the increase in insulin output. A similar situation occurs with glucose-stimulated islets $[15,20]$. However, we recently reported that the inclusion of nonradioactive inositol improved our ability to kinetically monitor PI hydrolysis using this efflux methodology. Similar studies were conducted with KIC-stimulated islets and the following major observations were made: (a) nonradioactive inositol has no appreciable effect on insulin output 
(Fig. 2, left panel); (b) however, its inclusion results in a markedly amplified ${ }^{3} \mathrm{H}$ efflux response to KIC stimulation (Fig. 2, right panel); (c) nonradioactive inositol increases the levels of free ${ }^{3} \mathrm{H}$-inositol in both control and KIC-stimulated islets (Table 2); (d) finally, nonradioactive inositol attenuates the increase in islet levels of labelled inositol phosphates noted with KIC stimulation (Table 2). These findings suggest that an increase in ${ }^{3} \mathrm{H}$ efflux (primarily free ${ }^{3} \mathrm{H}$-inositol, Table 2 ) most accurately reflects increases in PI hydrolysis provided cold inositol is included in the medium. We further suggest that cold inositol competes with labilised free ${ }^{3} \mathrm{H}$-inositol (derived from ${ }^{3} \mathrm{H}-\mathrm{PI}$ ) for reincorporation back into PI. The fact that nonradioactive inositol increased islet levels of free ${ }^{3} \mathrm{H}$-inositol, increased ${ }^{3} \mathrm{H}$ efflux but reduced levels of labelled inositol phosphates agrees with this suggestion. By competing with this rapidly expanding pool of free ${ }^{3} \mathrm{H}$-inositol for reincorporation into $\mathrm{PI}$, nonradioactive inositol increases the pool of free ${ }^{3} \mathrm{H}$-inositol allowing more of this moiety to efflux from the islet and appear in the effluent. In the absence of nonradioactive inositol, however, reincorporation of ${ }^{3} \mathrm{H}$-inositol back into PI reduces efflux of the label from the islet but contributes to the islets' ability to maintain sustained increases in levels of labelled inositol phosphates (and perhaps insulin secretion as well) after stimulant presentation (Table 1 and 2).

The most cogent data supporting the concept that exposure to KIC results in a persistent increase in PI hydrolysis was obtained by directly measuring the accumulation of labelled inositol phosphates during and after KIC stimulation (Table 1). The results demonstrate that $\mathrm{KIC}$ rapidly increases $I \mathrm{P}_{1}, \mathrm{IP}_{2}$ and $I \mathrm{P}_{3}$ levels in islets. Removal of KIC is paralleled by a reduction (although not to prestimulatory values) in the islet content of these compounds. Part of the persistent ${ }^{3} \mathrm{H}$ efflux response observed from these prior KIC stimulated islets may be the result of the degradation of these preformed inositol phosphates and/or the efflux of intracellular free inositol (Table 2). However, if these previously KIC-treated islets are subsequently perifused with lithium chloride, cellular levels of these inositol phosphates are elevated above those noted in control, non-KIC treated islets. The results obtained in the presence of lithium (Table 1) support the concept that prior $\mathrm{KIC}$ stimulation results in a persistent increase in PI hydrolysis via biochemical mechanisms that remain to be elucidated. When taken together with our other reports on the same topic, one is left with the impression that PI hydrolysis participates in agonistinduced insulin output and primes the B cell to any subsequent stimulation. Considering the inate complexity of events associated with PI hydrolysis [24], it is not yet possible to define precisely how insulin secretion and TDP are induced by PI-derived second messenger molecules. This promises to remain a fertile area for future studies.
Acknowledgements. These studies were supported by the American Heart Association 84-709. The expert technical assistance of K.C.Zawalich and V.A. Diaz, as well as the expert secretarial of Ms. J. Fettes, is gratefully acknowledged.

\section{References}

1. Grodsky GM, Curry D, Landahl H, Bennett LL (1969) Further studies on the dynamic aspects of insulin release in vitro with evidence for a two compartmental storage model. Acta Diabetol Lat 6 [Suppl 1]: 554-579

2. Grill V, Adamson U, Cerasi E (1978) Immediate and time-dependent effects of glucose on insulin release from rat pancreatic tissue. Evidence for different mechanism of action. J Clin Invest 61: 1034-1043

3. Grill V (1981) Time and dose dependencies for priming effect of glucose on insulin secretion. Am J Physiol 240: E24-E31

4. Cerasi $E$ (1975) Potentiation of insulin release by glucose in man: role of the insulin response and enhancement of stimuli other than glucose. Acta Endocrinol 79: 502-510

5. Zawalich WS, Diaz VA (1987) Prior cholecystokinin exposure sensitizes islets of Langerhans to glucose stimulation, Diabetes 36: $118-122$

6. Zawalich WS, Diaz VA, Zawalich KC (1988) Role of phosphoinositide metabolism in the induction of memory in isolated rat islets. Am J Physiol 254: E609-E616

7. Zawalich WS, Diaz VA, Zawalich KC (1987) Cholecystokinin-induced alterations in beta cell sensitivity: duration, specificity and involvement of phosphoinositide metabolism. Diabetes 36 : $1420-1424$

8. Fex G, Lernmark A (1975) Effects of insulin secretagogues on phospholipid metabolism in pancreatic B-cells. Biochem Biophys Acta 388: 1-4

9. Best L, Malaisse WJ (1983) Effects of nutrient secretagogues upon phospholipid metabolism in rat pancreatic islets. Mol Cell Endocrinol 32: 205-214

10. Best L (1986) A role for calcium in the breakdown of inositol phospholipids in intact and digitonin-permeabilized pancreatic islets. Biochem J 238: 773-779

11. Lacy PE, Kostianovsky M (1967) Method for the isolation of intact islets of Langerhans from the rat pancreas. Diabetes 16: $35-39$

12. Albano JDM, Ekins RP, Maritz G, Turner RC (1972) A sensitive, precise radioimmunoassay of serum insulin relying on charcoal separation of bound and free moieties. Acta Endocrinol 70: 487-509

13. Berridge MJ, Dawson RMC, Downes CP, Heslop JP, Irvine RF (1983) Changes in the level of inositol phosphates after agonistdependent hydrolysis of membrane phosphoinositides. Biochem J 212: 473-482

14. Zawalich WS, Takuwa N, Takuwa Y, Diaz VA, Rasmussen H (1987) Interactions of cholecystokinin and glucose in rat pancreatic islets. Diabetes 36: 426-433

15. Zawalich WS, Zawalich KC (1988) Phosphoinositide hydrolysis and insulin release from isolated perifused rat islets: studies with glucose. Diabetes (in press)

16. Zawalich WS, Zawalich KC (1988) Induction of memory in rat pancreatic islets by tolbutamide. Dependence on ambient glucose level, calcium, and phosphoinositide hydrolysis. Diabetes $37: 816 \cdots 823$

17. Hallcher LM, Sherman WR (1980) The effects of lithium ion and other agents on the activity of myo-inositol-1-phosphatase from bovine brain. J Biol Chem 255: 10896-10901

18. Sorenson RLC (1986) Islet priming by phorbol ester. Horm Metab Res 18: 353-354

19. Clements RS Jr, Evans MH, Pace CS (1981) Substrate requirements for the phosphoinositide response in rat pancreatic islets. Biochem Biophys Acta 674: 1-9 
20. Axen KV, Schubart UK, Blake AD, Fleischer N (1983) Role of $\mathrm{Ca}^{2+}$ in secretagogue-stimulated breakdown of phosphatidylinositol in rat pancreatic islets. J Clin Invest 72: 13-21

21. Clements RS Jr, Rhoten WB (1976) Phosphoinositide metabolism and insulin secretion from isolated rat pancreatic islets. J Clin Invest $57: 684-691$

22. Anderson JH, Blackard WG (1979) Effect of lithium on pancreatic islet insulin release. Endocrinology 102: 291-295

23. Fontela T, Hermeda OG, Gomez-Acebo J (1987) Dihydroergotamine but not naloxone counteracts lithium as an inhibitor of glucose-induced insulin release in isolated rat islets in vitro. Diabetologia 30: 183-187

24. Zawalich WS (1988) Modulation of insulin secretion by phosphoinositide-derived second-messenger molecules. Diabetes 37: 137-141
25. Borle A, Uchikawa T, Anderson JH (1982) Computer simulation and interpretation of ${ }^{45} \mathrm{Ca}$ efflux profile patterns. J Membr Biol 68: $37-46$

Received: 28 December 1987

and in revised form: 26 April 1988

Dr. W.S. Zawalich

Yale University School of Nursing

855 Howard Avenue

P.O. Box 9740

New Haven, CT 06536-0740

USA 